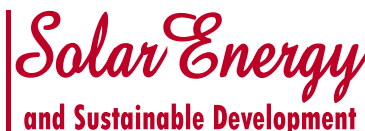 \\ Refereed, biannual scientific journal Issued br
}

\section{Solar Hydrogen System Configuration Using Genetic Algorithms}

\author{
I. O. Mohamed \\ Engincering College Tajoura - Libya \\ cmail: ibrahim irhoma@yahoo.co.tek
}

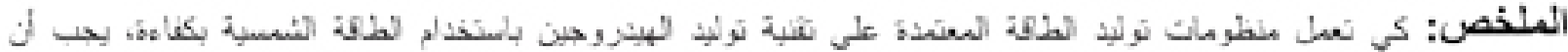

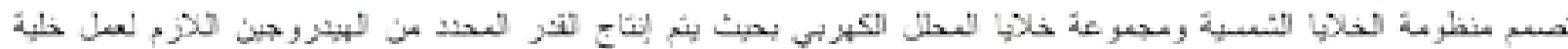

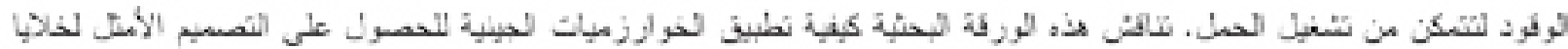

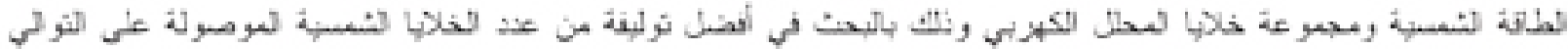

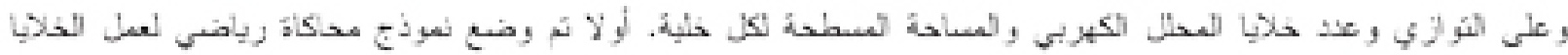

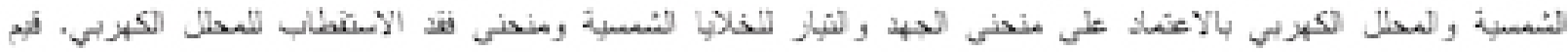

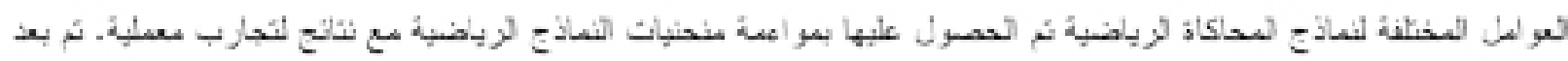

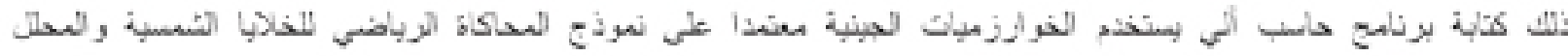

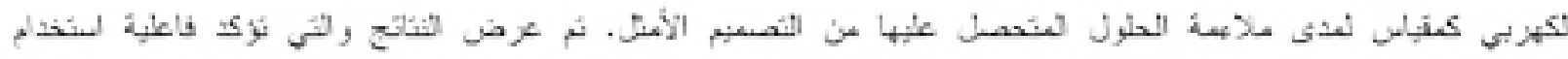

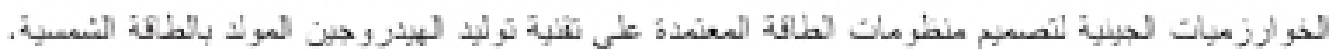

\begin{abstract}
For standalone power supply systems based on solar hydrogen technology to work efficiently, the photovoltaic generator and electrolyser stack have to be configured so that they produce the needed amount of hydrogen in order for the fuel cell to produce sufficient power to operate the load. This paper discusses how genetic algorithms were applied to optimise the design of the photovoltaic generator and electrolyser combination by searching for the best configuration in terms of number of parallel and series PV modules, number of electrolyser cells, and cell surface area. First, a mathematical simulation model based on the current-voltage PV characteristics and the polarisation characteristics of the electrolyser was developed. The models parameters were obtained by fitting the mathematical models to experimental data. A genetic algorithm code was then developed. The code is based on the PV and electrolyser models as an evaluation measure for the fitness of the solutions generated. Results are presented confirming the effectiveness of using the genetic algorithm technique for solar hydrogen system configuration.
\end{abstract}

Keywords: Hydrogen, Modelling, Photovoltaics, Electrolyser, Genetic algorithms

\section{INTRODUCTION}

As an energy carrier hydrogen has attracted interest in most of the world in the last few decades [1]. Research results have indicated that it could replace fossil fuels in many of their uses such as heating, transportation, and electricity generation, for residential as well as industrial applications [2, 3]. The most attractive features of hydrogen are that it is a nonpolluting energy carrier, and it could be produced by variety of methods [4].

Renewable energies in general and solar energy in particular are of steadily 
increasing importance as an energy source across all over the world. This makes the solar hydrogen system one of the most interesting options for the sustainable energy future [5].

In solar hydrogen systems, the PVelectrolyser combination has to be carefully designed to assure a good match between their characteristics. This is important to make use of the maximum PV power output to operate the electrolyser; otherwise valuable energy will be lost by the mismatch.

To accomplish this, five parameters, related to the design of the $\mathrm{PV}$ and electrolyser stack, have to be optimised. These are the PV cell area, the number of series connected PV cells, the number of parallel connected PV cells, the electrolyser's cell area and how many of these cells should be connected together in series and parallel. There is a wide range of possible choices. Doing the optimisation process manually can take a long time and the solution obtained may not be the best one available. Hence a Genetic Algorithm optimisation was used.

The benefits of GA optimisation technique over conventional methods lie in its globalisation nature during the search process. The conventional methods usually produce results that are highly dependent on a starting point or an initial guess, while $\mathrm{GA}$ is largely independent of the initial condition. In addition to this, for the conventional methods the existence of the analytical solution to the problem is necessary. This is not essential if GA technique is used. This makes the use of GA more efficient in dealing with complex problems having large number of dimensions and constrained parameters.

\section{COMPONENTS MODELING}

\subsection{PV cell mathematical model}

Figure 1 adapted from $[6,7]$ shows an equivalent circuit of a solar cell, consisting of the current source, diode, series resistance, and shunt resistance. The equivalent circuit can be used to model a single cell, a module, or for an array as well.

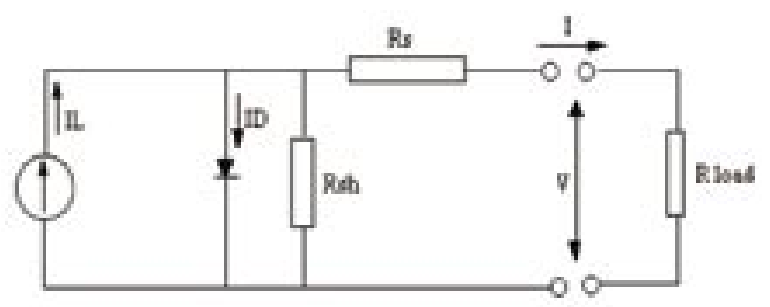

Figure 1: The equivalent circuit of a PV cell

The current-voltage characteristics of this circuit will form the mathematical model representing the solar cell and be used for simulation and computation purposes. The model has the following form $[7,8$, and 9$]$ :

$$
\begin{aligned}
& I=\left[I_{L}-I_{O}\left(\exp \left(L\left(V+I R_{x}\right)\right)-1\right)-\right. \\
& \left.V / R_{x h}\right] / \beta .
\end{aligned}
$$

\subsection{Electrolyser mathematical model $[10,11$, and 12$]$}

The current voltage curve normally characterises the performance of an electrolyser. At ambient pressure and temperature the minimum amount of potential needed to perform the separation of water into hydrogen and oxygen is $1.229 \mathrm{~V}$. However, this is not the case in practical life, i.e. when an electrolyser is made and put to work; the separation voltage is found to be higher than the theoretical one. This is due to a number of irreversibilities. The most significant two are the activation losses at the electrodes and the ohmic losses due to the electrolyte and electrodes material. Operating temperature has an influence on the cell performance and it has to be considered as well. Equation 2 is the best nonlinear fit that describes the current-voltage characteristics of an electrolyser, which takes into account all the factors affecting the cell performance

$$
\begin{aligned}
V= & Z\left(V_{\text {th }-}-C_{1} \theta\right)+\left(R-C_{2} \theta\right)(Z L / F)+ \\
& C_{3} Z \ln (\mathrm{V} / F)
\end{aligned}
$$




\section{MATHEMATICAL MODELS FITTING}

For the mathematical models given by equations 1 and 2 to be used for the system simulation and design, the values of the following parameters have to be obtained: $\mathrm{I}_{\mathrm{L}}, \mathrm{I}_{\mathrm{O}}, \mathrm{n}, \mathrm{R}_{\mathrm{s}}, \mathrm{R}_{\text {sh. }}, \mathrm{V}_{\text {th }}, \mathrm{R}, \mathrm{C}_{1}, \mathrm{C}_{2}, \mathrm{C}_{3}$. To accomplish this, an experiment was set up based on an educational solar hydrogen test rig. A sketch of the apparatus is shown in figure 2. In this test rig, a solar module of four cells was used to power a $25 \mathrm{~cm}^{2}$ electrolyser to produce hydrogen at a maximum rate of $28 \mathrm{ml} / \mathrm{min}$. The hydrogen is stored in a cylindrical tank ready for use by two fuel cells to generate electricity. To examine the components at different loads, selectable resistances ranging from $0.3 \Omega$ to $100 \Omega$ are connected to the components terminals. Current and voltage at each load are displayed on LCD panels of a digital ammeter/voltmeter.

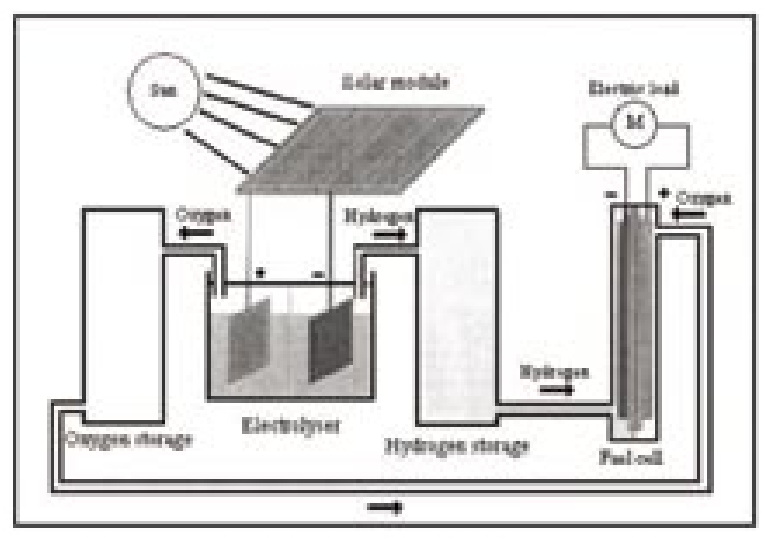

Figure 2: Sketch of a PV- $\mathrm{H}_{2}$ test rig.

Successive measurements of the components current and voltage were recorded for different loads. The experimentally measured $\mathrm{I}-\mathrm{V}$ data were fitted to equations 1 and 2. This was accomplished by a computer code developed using the optimisation toolbox of the MATLAB software. All the parameters in equations 1 and 2 were left free. Values obtained of the parameters agreed well with those found in the literature and are given in tables 1 and 2 while figures 3 and 4 show the current voltage experimental data and models plot of the solar module and the electrolyser.

\section{PV-ELECTROLYSER STACK CONFIGURATION}

A recent research project was aimed to design a power supply system to provide electricity for a single dwelling in a remote area of a developing country. The system used solar hydrogen technology, where a fuel cell stack was be used to convert hydrogen into electricity. The hydrogen will be produced by an electrolyser powered by solar PV panels. The system load was estimated to be $730 \mathrm{kWh} /$ year requiring 1000 normal litres of hydrogen daily

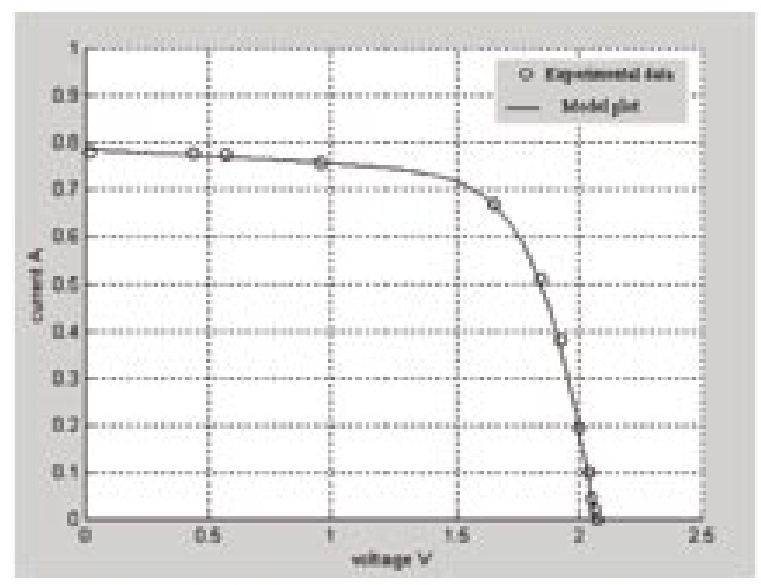

Figure 3: Solar module current voltage experimental data and model plot

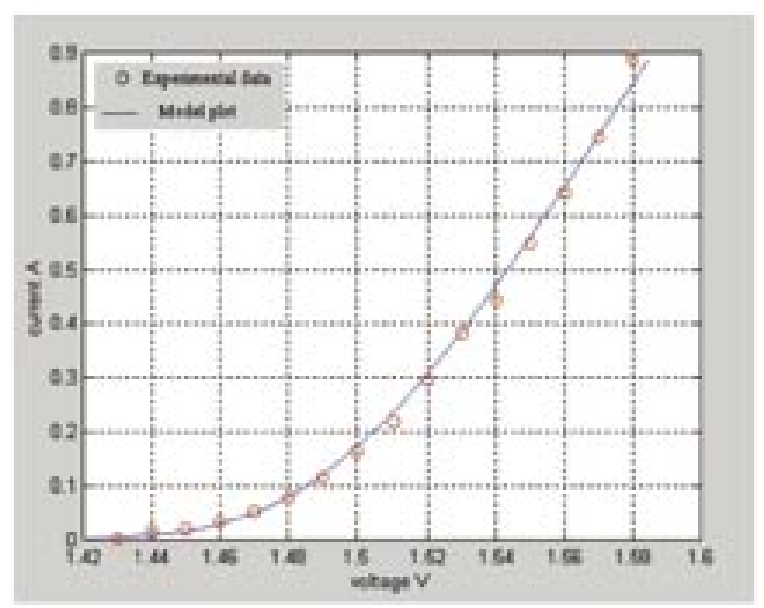

Figure 4: Electrolyser current voltage experimental data and model plot

The task was to configure the PV panels and electrolyser's stack so that they fulfil 
the design requirements of delivering the right amount of hydrogen. In addition, the PV-electrolyser combination should be of acceptable physical size to be used in a family house. However, numerous trials were necessary in order to choose the optimal design parameters (number of PV cells in series and in parallel and the cell's surface area as well as number of electrolyser cells in series and in parallel and their surface area). In order to overcome this problem, genetic algorithms were used.

Table 1: Solar module model fitted parameters

\begin{tabular}{|c|c|}
\hline Parameter & Value \\
\hline Module photo current $I_{L}$ & 0.79 Amps \\
\hline Module saturation current $I_{O}$ & $\begin{array}{c}3.45 \times 10^{-7} \\
\text { Amps }\end{array}$ \\
\hline $\mathrm{N}$ & 2.7 \\
\hline Module series resistance $R_{S}$ & 0.11 Ohms \\
\hline Module shunt resistance $R_{t h}$ & 31.72 Ohms \\
\hline
\end{tabular}

Table 2: Electrolyser model fitted parameters

\begin{tabular}{|c|c|}
\hline Parameter & Value \\
\hline $\begin{array}{c}\text { Cell theoretical voltage } \mathrm{V}_{\text {由 }} \\
\text { Theoretical voltage } \\
\text { parameter } \mathrm{C}_{1}\end{array}$ & 1.45 Volts \\
\hline Cell resistance $\mathrm{R}$ & $\begin{array}{c}2.07 \times 10^{-4} \\
\text { Ohms }\end{array}$ \\
\hline $\begin{array}{c}\text { Cell resistance parameter } \mathrm{C}_{2} \\
\text { Activation losses parameter } \\
\mathrm{C}_{3}\end{array}$ & $1.56 \times 10^{-7}$ \\
\hline
\end{tabular}

\section{PV-ELECTROLYSER STACK DESIGN USING GAS}

Genetic algorithms are search methods that can be used to solve optimisation problems by implementing powerful search techniques to find an optimal solution within a large search space (possible solutions to the problem).

Genetic Algorithm techniques are based on natural biological evolution [13]. A genetic algorithm works by generating a large set of possible solutions to a given problem. It then evaluates each of these solutions, and decides on a "fitness level" which is closer to the optimal solution. These solutions then breed new solutions. The parent solutions that were more fit are more likely to reproduce, while those that were less fit are less likely to do so. GA operators, mainly crossover and mutation, achieve the reproduction of solutions [14].

Crossover combines the features of two parent chromosomes (solutions) to form two new similar children (new solutions) by swapping corresponding segments of parents [15]. Mutation is done by randomly changing one or more genes (parameters within a solution), by a random change with a probability equals to mutation rate. Crossover is aimed at exchanging information between different potential solutions, while mutation is aimed at introducing some extra variability into the population [16].

To design the PV and electrolyser's stack using genetic algorithms, or in other words to optimise the five design parameters, a MATLAB computer code was developed. The code starts with generating solutions by randomly selecting values for the design parameters between upper and lower limits provided by the designer. These solutions are evaluated using the fitness function. The fitness function is based on the components mathematical models given by equations 1 and 2 . The solutions are inserted into the models, and the I-V characteristics are calculated. The penalty approach [16] was used to penalise solutions not producing the required amount of hydrogen. Those that do so are ranked using a linear rank selection technique [14]. Then, a stochastic universal sampling method [16] is used to select some of the good solutions to form a new population of solutions. Crossover and 
mutation are then applied to the selected solutions to produce new offsprings. This process continues till the specified number of generations is reached.

A flowchart of the steps of the genetic code used to get the optimal parameters is shown in Figure 5. The parameters values of genetic algorithms used are given in Table 3. Table 4 gives the upper and lower limits of the optimised parameters.

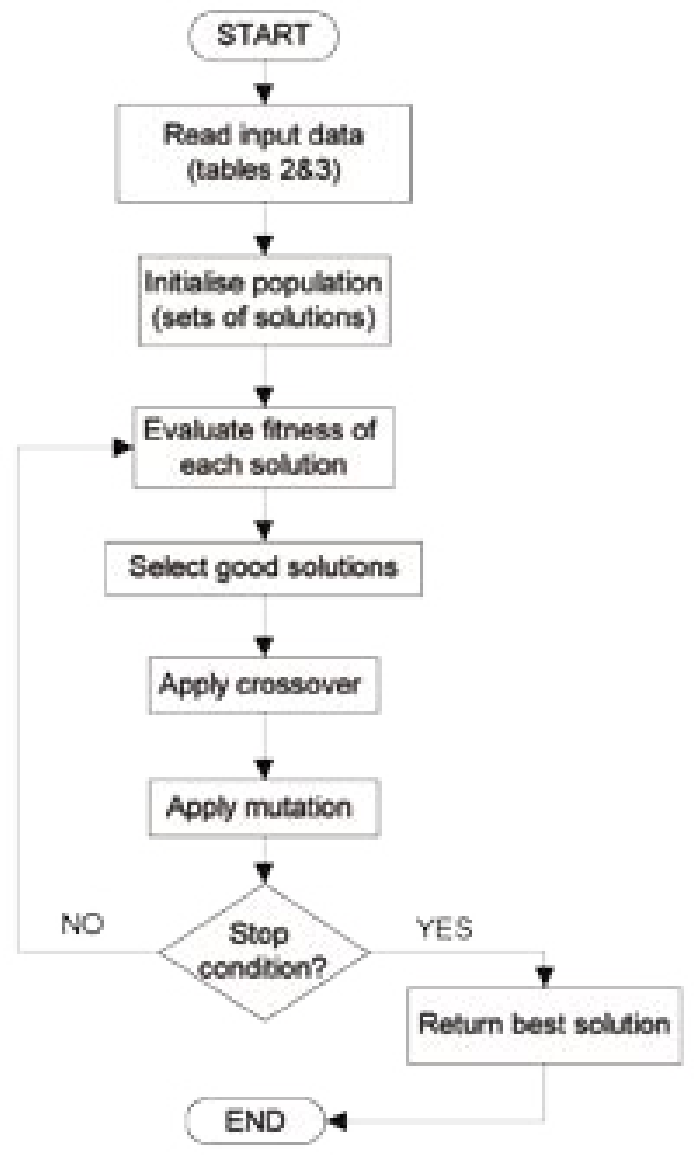

Figure 5: The genetic code to obtain the system's optimal parameters.

Table 3: Values of GA parameters

\begin{tabular}{|c|c|}
\hline Parameter & Value \\
\hline Population size & 20 \\
\hline $\begin{array}{c}\text { Maximum number of } \\
\text { generations }\end{array}$ & 200 \\
\hline Number of problem variables & 5 \\
\hline Crossover rate & $90 \%$ \\
\hline Mutation rate & $10 \%$ \\
\hline
\end{tabular}

Table 4: Upper \& lower values of the parameters to be optimised (search space)

\begin{tabular}{|c|c|c|}
\hline Parameter & $\begin{array}{c}\text { Lower } \\
\text { limit }\end{array}$ & $\begin{array}{c}\text { Upper } \\
\text { limit }\end{array}$ \\
\hline $\begin{array}{c}\text { Number of PV series } \\
\text { connected cells }\end{array}$ & 20 & 100 \\
\hline $\begin{array}{c}\text { Number of PV parallel } \\
\text { connected cells }\end{array}$ & 1 & 20 \\
\hline $\begin{array}{c}\text { PV cell area (m²) } \\
\text { Number of lectrolyser } \\
\text { connected cells }\end{array}$ & 0.01 & 0.01 \\
\hline $\begin{array}{c}\text { Electrolyser cell surface } \\
\text { area (m }\end{array}$ & 0.01 & 0.16 \\
\hline
\end{tabular}

\section{RESULTS}

By executing the PV-Electrolyser's stack design genetic code, solutions were generated, evaluated for their fitness, and then genetically modified to converge to the optimal parameter values. Figure 6 shows the average fitness of the twenty solutions processed at each generation. Here the lower the fitness value the better the solution is. This is so because the fitness is measured in terms of the total PV surface area required to power the electrolyser. It is clear that as the number of generations approaches the end, the code gets closer to the optimal solution. Figure 7 illustrates the fitness of the best solution within each generation.

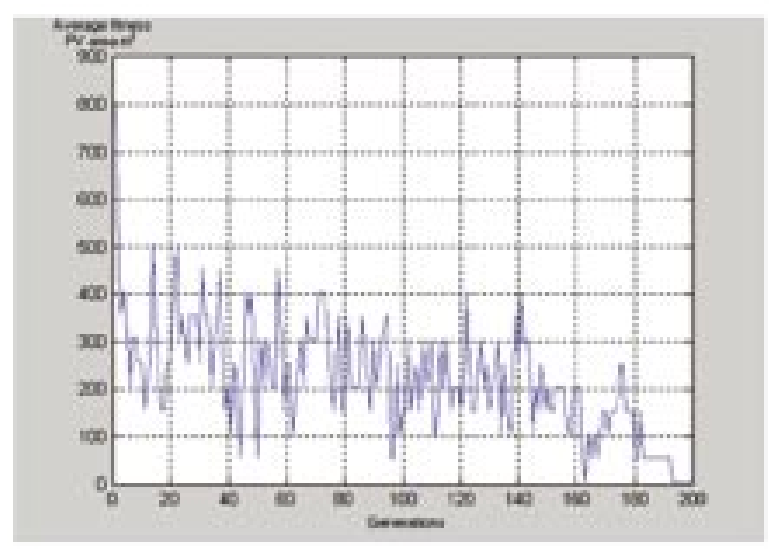

Figure 6: Solutions of average fitness 


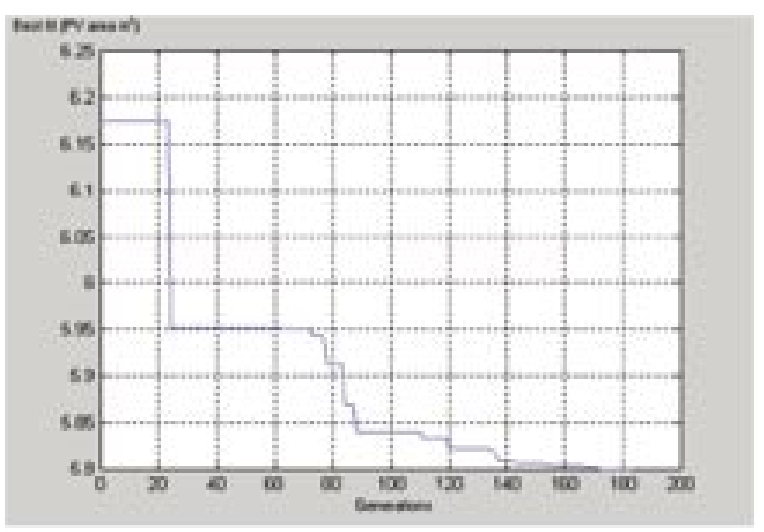

Figure 7 : Fitness of best solution during the generations

In order to verify the performance of the PV- electrolyser hydrogen producing system designed using genetic algorithms, the optimal design parameters values were fed back to the mathematical models of the two components to perform a one year performance simulation.

Figure 8 demonstrates this and shows the effectiveness of the GA optimisation. This is clear as the electrolyser curve passes near to the maximum power points of the PV panels. Hence, less power is wasted and consequently a smaller PV area is required in the design.

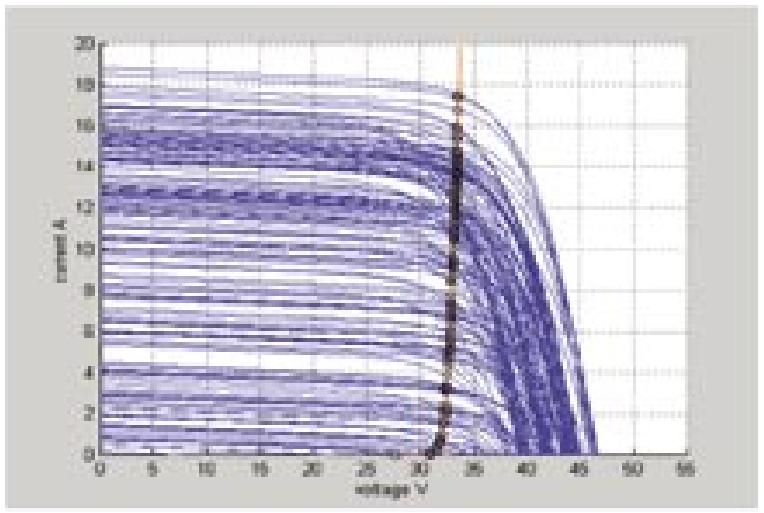

Figure 8: I-V characteristics of PV and electrolyser using GA results

\section{CONCLUSION}

In this paper, mathematical characteristic curve models for solar photovoltaic panels and hydrogen producing electrolyser were presented. The models were verified against experimental data, and offer a very useful tool for solar hydrogen system behaviour simulation. The paper also described how a PV. electrolyser combination can be configured using genetic algorithms. A genetic algorithm code was developed using MATLAB. The code evaluation function was based on the simulation models as a measure for the solutions fitness. For the design case studied in this paper, the genetic code took few minutes to arrive to an optimal solution. This solution was verified by feeding it to the components models and performing a one year currentvoltage characteristic simulations.

\section{NOMENCLATURE}

I Module current in amps

$V$ Module voltage in volts

$I_{I}=\mathrm{F}_{1} \cdot \mathrm{F} \cdot \mathrm{P} \cdot\left(0.28+21 \times 10^{-5} \mathrm{~T}\right) \cdot \mathrm{R}$

$I_{1}$ Module photo current in amps

$F_{L} \quad$ Module photocurrent coefficient in amps/W

$F$ Solar cell surface area in $\mathrm{cm}^{2}$

$P \quad$ Number of parallel connected solar cells

$R$ Solar radiation on the solar panel in $W / \mathrm{cm}^{2}$

$I_{0}=\mathrm{F}_{0} \mathrm{~F} \cdot \mathrm{P} \cdot \mathrm{T}^{3} \cdot \exp \left(-\mathrm{E}_{p} / \mathrm{KT}\right)$

Io Module saturation current in Amps

$F_{O}$ Module saturation current cocfficient in $\operatorname{amps} / \mathrm{cm}^{2} \cdot \mathrm{K}^{3}$

$T$ Solar cell working temperature in $\mathrm{K}$

$E_{p}$ Band gap energy (J)

$k$ Boltmmann's constant $=1.38066 \times 10^{-23} \mathrm{~J} / \mathrm{K}$

$\beta=1+R, / R_{, h}$

$R$, Module series resistance in ohms

$R_{\text {sh }} \quad$ Module shunt resistance in ohms

$L \quad=q / A k T$

Q Electron charge $=1.6022 \times 10^{-19} \mathrm{~J}$

$A \quad=n . S$

$S \quad$ Number of series connected cells

$n \quad$ Cell junction perfection factor

$\mathrm{V}$ Operating voltage in volts

Z Number of cells connected in series 
$V_{\text {th }} \quad$ Cell theoretical voltage in volts

$\mathrm{C}_{1} \quad$ Theoretical voltage coefficient

$\theta \quad$ Cell operating temperature in ${ }^{\circ} \mathrm{C}$

$\mathrm{R} \quad$ Cell resistance in ohms

$\mathrm{C}_{2} \quad$ Cell resistance coefficient

I Operating current in amps

$\mathrm{F} \quad$ Cell surface area in $\mathrm{m}^{2}$

$C_{3}$ Electrodes over voltage coefficient

\section{REFERENCES}

[1]. T. Nejat Veziroglu, (2000) "Quarter century of hydrogen movement 1974 $-2000 "$. International Journal of Hydrogen Energy, Vol. 25, pp. 11431150.

[2]. Joan M. Ogden, (1999) "Prospects for building a hydrogen energy infrastructure". Annual Review of Energy and the Environment, Vol. 24, pp 227-279.

[3]. J. Quakernaat, (1995) "Hydrogen in a global long term prospective". International Journal of Hydrogen Energy, Vol. 20, pp. 486-492.

[4]. Daniel Sperling, and James S. Cannon, (2004), "The hydrogen energy transition". Elsevier Academic Press.

[5]. Laszlo Fabri, (1996),"Future fuel be solar hydrogen". Periodica Polytechnica Mechanical Engineering, Vol. 40, pp. 77-84.

[6]. John A. Duffie, William A. Beckman, (1991), "Solar engineering of thermal processes". John Wiley \& Sons Inc.

[7]. Tom Markvart and Luis Castaner, (2005),"Solar cells: Materials, manufacturing. and operation". Elsevier.
[8]. Tom Markvart and Luis Castaner, (2003),"Practical Handbook of Photovoltaics: Fundamentals and Applications. Elsevier.

[9]. Luis Castaner and Santiago Silvestre, (2002),"Modelling Photovoltaic Systems using PSpice, John Wiley \& Sons Ltd.

[10]. J. P. Vanhanen, P. S. Kauranen, P. D. Lund, AND L. M. Manninen, (1994) "Simulation of solar hydrogen systems". Solar energy, Vol, 53, No. 3. pp. 267-278.

[11]. Carl-Jochen Winter, Joachim Nitsch, (1988). "Hydrogen as an Energy Carrier: technologies, systems, economy". Springer-Verlag.

[12]. C. Carpetis, (1984) "An assessment of electrolytic hydrogen production by means of photovoltaic energy conversion". International journal of hydrogen energy, Vol. 9, No. 12, pp 969-991.

[13]. David Lawrence, (1991), Handbook of genetic algorithms, Van Nostrand Reinhold.

[14]. Melanie Mitchell, (1999), An introduction to genetic algorithms, The MIT Press.

[15]. G. Winter, J. Periaux, M. Galan, (1995), Genetic algorithms in engineering and computer scince, John Wiley \& Sons.

[16]. Zbigniew Michalewicz, (1994), Genetic algorithms + data structures $=$ Evolution programs, SpringerVerlag. 